\title{
Comparison of postural balance between professional tae kwon do athletes and young adults
}

\author{
Comparação do equilibrio postural entre atletas profissionais de tae kwon do \\ e adultos jovens
}

\author{
Comparación del equilibrio postural entre los atletas profesionales en tae kwon do \\ $y$ adultos jóvenes
}

Lucas Maciel Rabello4, Christiane de Souza Guerino Macedo², André Wilson Gil', Marcio Rogério de Oliveira', Vinícius Arantes Coelho', Gustavo Balthazzar Silva', Rubens Alexandre da Silva Jr. ${ }^{3}$

\begin{abstract}
I This study aimed to compare the postural balance of professional tae kwon do athletes with a non-tae kwon do adult group. Nineteen participants (nine tae kwon do practitioners and ten non-tae kwon do practitioners) were tested. To measure the postural sway, a force platform was used and the equipment recorded the main parameters: area of center of pressure; mean frequency, and velocity of center of pressure for both anteroposterior and mediolateral directions were measured for all participants. Before starting the assessment, the subjects received instructions and performed familiarization with the equipment and protocol. Participants were instructed to carry out three balance tests on a single-leg stance position with eyes opened. Values obtained in the postural assessment of professional athletes with the force platform were lower for all parameters compared to non-practitioners, except the frequency of center of pressure in the mediolateral direction. However, a significant difference $(p=0.021)$ between the groups was found only in the center of pressure velocity parameter in the anteroposterior direction. These results have any implications on sport rehabilitation programs for balance assessments in athletes.
\end{abstract} Keywords I Martial Arts; Postural Balance; Athletes.
RESUMO I Este estudo teve como objetivo comparar o equilíbrio postural de atletas profissionais de tae kwon do com um grupo de adultos não praticantes do esporte. Dezenove participantes (nove praticantes profissionais de tae kwon do e dez não praticantes) foram testados. Para avaliar a oscilação postural, uma plataforma de força foi utilizada e o equipamento registrou os principais parâmetros: área do centro de pressão; frequência e velocidade do centro de pressão tanto para a direção anteroposterior, quanto para a médio-lateral. Essas medidas foram registradas para todos os participantes. Antes de iniciar a avaliação, os sujeitos receberam orientações e se familiarizaram com o equipamento e o protocolo. Também foram instruídos a realizar três testes de equilibrio em apoio unipodal com os olhos abertos. Os valores obtidos na avaliação postural de atletas profissionais com o uso da plataforma de força foram inferiores para todos os parâmetros, quando comparados com aqueles dos não praticantes, com exceção da frequência do centro de pressão para a direção médio-lateral. No entanto, encontrou-se uma diferença significativa $(p=0,021)$ entre os grupos somente no parâmetro da velocidade anteroposterior do centro de pressão. Esses resultados apresentam implicações nos programas de reabilitação esportiva para avaliação do equilibrio postural em atletas. Descritores I Artes Marciais; Equilíbrio Postural; Atletas.

\footnotetext{
Study developed at the Center for Health Sciences Research, Laboratory of Functional Evaluation and Human Motor Performance (LAFUP), Universidade Norte do Paraná (UNOPAR) - Londrina (PR), Brazil.

'Physiotherapists and MSc at the LAFUP, UNOPAR; Master's and Doctoral Programs in Rehabilitation Sciences at Universidade Estadual de Londrina (UEL), UNOPAR - Londrina (PR), Brazil.

${ }^{2}$ Professor at the Physical Therapy Program, Center for Health Sciences (CCS), UEL - Londrina (PR), Brazil.

${ }^{3}$ Titular Professor at the LAFUP, UNOPAR; Master's and Doctoral Programs in Rehabilitation Sciences at UEL/UNOPAR;

${ }^{4}$ Coordinator of Physiotherapy, Faculty of Education and Environment, Ariquemes (RO), Brazil.
} 
RESUMEN I Este estudio tuvo como objetivo comparar el equilibrio postural de atletas de tae kwon do profesionales con un grupo de adultos que no practican esto deporte. Diecinueve participantes (nueve practicantes profesionales de tae kwon do y diez no practicantes) se pusieron a prueba. Para evaluar la oscilación postural, se utilizó una plataforma de fuerza y el equipo registró los parámetros principales: el centro de la zona de presión; la frecuencia y la velocidad del centro de la presión tanto para la dirección anteroposterior, y para la medio-lateral. Estas mediciones se registraron para todos los participantes. Antes de iniciar la evaluación, los sujetos recibieron instrucciones y se familiarizaron con el equipo y el protocolo. También fueron instruidos para realizar tres pruebas de equilibrio en un solo pie con los ojos abiertos. Los valores obtenidos en la evaluación postural de los atletas profesionales utilizando la plataforma de fuerza eran más bajos para todos los parámetros en comparación con aquellos de los no profesionales, con la excepción de la frecuencia del centro de presión de la dirección medial-lateral. Sin embargo, se encontró una diferencia significativa ( $p=0,021)$ entre los grupos sólo con respecto a la velocidad anteroposterior del centro de presión. Esos resultados tienen implicaciones para los deportes de los programas de rehabilitación para la evaluación del equilibrio postural en los atletas.

Palabras clave I Artes Marciales; Balance Postural; Atletas.

\section{INTRODUCTION}

Tae kwon do (TKD), an official Olympic sport, is a popular martial art in Korea (country of origin), winning new practitioners over the years around the world. It is characterized by rapid movements of attack and defense, with greater emphasis on dynamic kicking techniques from a mobile position ${ }^{1}$. To perform the tasks required in this sport, physical abilities such as strength, speed, endurance, balance, flexibility, and coordination are essential for the athletic performance ${ }^{2}$. Among them, postural balance is essential to the practice of TKD techniques since most of the movements are performed on one-leg support. The deficit of postural balance may lead to system body instability, overload passive musculoskeletal structures and consequently to disorders, pain, and falls. In fact, approximately 3.9\% of the neuromuscular and orthopedics disorders come from neuromuscular balance defictis ${ }^{3}$. In a recent study, which evaluated the incidence of muscular disorders in professional athletes of the Canadian TKD team, the authors observed that athletes experiencing some injury during a fight decreased their chances to reach a medal (88.0\% of cases on competitions) $)^{4}$.

For an efficient performance on TKD skills, athletes need to preserve and develop more postural balance. Techniques such as kicks, jumps and quick changes in any directions trainee the sensory and motor systems of these athletes for new adaptations of postural control. Biomechanically speaking, balance is defined as the capacity of an individual to place his/her center of mass of the body, corresponding to the projection of his/her center of gravity, within his/her support base ${ }^{5-7}$. This process is complex and based on postural control from stimulus and responses derived of three systems: visual, vestibular, and somatosensory ${ }^{8}$. The influence of TKD practice on postural balance is thus largely studied in various nonprofessional individuals like children, adolescents $^{9}$, adults ${ }^{10}$, and aged people ${ }^{11}$. However, in professional athletes, balance investigation frequently pointed out in sports such as dance ${ }^{12}$, gymnastic ${ }^{13}$, and judo ${ }^{14}$. New studies still need to assess postural balance in TKD professional athletes.

The aim of this study was to compare postural balance of TKD professional athletes with young healthy adults without TKD experience. The investigated hypothesis is that professional athletes would present a better balance when compared to untrained individuals.

\section{METHODS}

The sample consisted of 19 healthy participants aged between 19 and 31 years, from both sexes. The TKD Group (TKDG) included nine professional athletes (five men and four women) with a mean age of 24 years (standard deviation $-\mathrm{SD}=4.28$ years old). The Control Group (CG) was composed of ten young adults (six men and four women) with a mean age of 23 years $(\mathrm{SD}=4.11$ years old). All participants were recruited voluntarily and by convenience. All the athletes of TKDG were members of the Brazilian TKD team in preparation to Pan-American Games (2011) and of the World TKD Federation (WTF).

The inclusion criteria to TKDG were as follows: performance of specific training daily and participation in national and/or international competitions. For the CG, they were: non-participation in any specific sports training and to be healthy. For both groups, 
general exclusion criteria were: history of systemic diseases and diseases that affect joint structures, especially in the lower limbs; presence of any disability (orthopedic or neurological); and surgeries performed in the locomotor system.

The Laboratory of Functional Evaluation and Human Motor Performance from the Universidade Norte do Paraná (LAFUP-Unopar) was the location of the study. The participants were informed about the experimental protocol and the potential risks of the study, and provided written consent before their participation. The protocol and the consent form had been previously approved by the local Ethics Committee (protocol PP/0231/10).

One session of approximately one hour was required in the laboratory (LAFUP - Unopar). The same investigator performed all procedures with the participants at the same place to ensure uniformity. Each subject was familiarized with the experimental protocol and the equipment.

Postural balance was assessed by a force platform (BIOMEC400, EMG System do Brasil, Ltda., São Paulo, Brazil). During all trials, the participants were instructed to stand on the leg of their preference under the following standardized condition. The athletes were barefoot placed standing on a force platform, at one-leg preference, looking to a mark at eye height, in front of the platform, trunk at erect position and upper limbs along the body, while the contralateral lower limb remained with hip at neutral position and knee at a $90^{\circ}$ flexion. Participants performed three 30 -second oneleg stance trials, with a rest period of approximately 30 seconds between each of them. The mean of three trials was used to increase the reliability of data as already well reported by Pinsault and Vuillerme ${ }^{15}$.

For all balance tests, the vertical ground reaction force signals from the force platform were sampled at $100 \mathrm{~Hz}$. They were filtered with a 35-Hz low-pass second-order Butterworth filter. The bio-analysis software of the BIOMEC400 platform itself, which is compiled with computer routines of stabilographic analyses in the MATLAB (The Mathworks, Natick, MA), was used for acquisition and treatment of the balance parameters. The main balance parameters analyzed were: ellipse area (95\%) of the center of pressure (COP) in square centimeters (A-COP in $\mathrm{cm}^{2}$ ), mean velocity in centimeters by second (VEL in $\mathrm{cm} / \mathrm{s}$ ), and mean frequency in Hertz $(\mathrm{MF}$ in $\mathrm{Hz}$ ) of $\mathrm{COP}$ oscillations in both directions of the movement: anteroposterior $(\mathrm{A} / \mathrm{P})$ and mediolateral (M/L). The validity and reliability of all these parameters computed with this typical force platform have been accepted for both young adults and elderly subjects, as reported by a recent study from our research team ${ }^{16}$.

The anthropometric variables were tested for normal distribution using Shapiro-Wilk's test. After confirming the normal distribution of data, the comparison between the groups for each dependent variable (A-COP, VEL and MF) was performed using the Student's $t$-test for independent samples. All statistical analyses were performed using the Statistical Package for Social Sciences - SPSS software (version 15, SPSS Inc., Chicago, IL), with an alpha of 0.05 for statistical significance.

\section{RESULTS}

The anthropometric characteristics of the participants are presented in Table 1 . There is no significant difference $(p>0.05)$ between the TKDG and CG in variables for age, mass, height, and body mass index (BMI).

Significant differences were found between the two groups for the postural balance (Table 2), which were then pointed out in the COP velocity parameter from $\mathrm{A} / \mathrm{P}$ direction of movement $(\mathrm{p}=0.02)$. The TKDG presented better balance than the CG (young adults), once the values of the latter were higher than for the TKDG.

Table 1. Characteristics of the subjects

$\begin{array}{lcc}\text { Variables } & \begin{array}{c}\text { TKDG }(n=9) \\ \text { Mean (SD) }\end{array} & \begin{array}{c}\text { CG }(n=10) \\ \text { Mean (SD) }\end{array} \\ \text { Age (years) } & 24.89(4.28) & 23.30(4.11) \\ \text { Mass (kg) } & 66.37(11.61) & 69.29(14.42) \\ \text { Height }(\mathrm{m}) & 1.74(0.09) & 1.71(0.09) \\ \text { BMl }\left(\mathrm{kg} / \mathrm{m}^{2}\right) & 21.94(2.70) & 23.28(3.03)\end{array}$

SD: standard deviation; TKDG: Tae kwon do Group; CG: Control Group; BMl: body mass index

Table 2. Comparison between groups in postural balance results

$\begin{array}{lccc}\text { Variables } & \begin{array}{c}\text { TKDG } \\ \text { Mean (SD) }\end{array} & \begin{array}{c}\text { CG } \\ \text { Mean (SD) }\end{array} & \text { p-value } \\ \text { A-COP }\left(\mathrm{cm}^{2}\right) & 5.09(1.28) & 6.23(\mathrm{O} .49) & 0.103 \\ \text { A/P VEL }(\mathrm{cm} / \mathrm{s}) & 1.95(0.30) & 2.35(0.77) & 0.021^{*} \\ \text { M/L VEL }(\mathrm{cm} / \mathrm{s}) & 2.24(0.75) & 2.39(0.44) & 0.425 \\ \text { A/P MF (Hz) } & 0.57(0.17) & 0.61(0.13) & 0.612 \\ \text { M/L MF (Hz) } & 0.79(0.19) & 0.77(0.12) & 0.749\end{array}$

SD: standard deviation; *significant difference ( $p<0.05$ ). TKDG: Tae kwon do Group; CG: Control Group; A-COP: area of center of pressure; VEL: mean velocity of the center of pressure: MF: mean frequency of the center of pressure; A/P: anteroposterior; M/L: mediolateral 


\section{DISCUSSION}

The results of the present study supported that TKD professional athletes present better postural balance when compared to young adults without TKD practice, when velocity of COP sway is of concern in the analysis. These results were in agreement, at least, to our hypothesis.

Force platform had been considered the goldstandard instrument for postural balance analysis, since it reveals direct neuromuscular and biomechanical mechanisms associated with postural control ${ }^{17}$. The velocity measure represents the magnitude of COP displacement over time. The routines were compiled from our system through a stabilographic analysis. With the MATLAB (The Mathworks, Natick, MA), we extracted all of the COP parameters, with regard to procedure of previous studies ${ }^{15-19}$ for computing of the $95 \%$ confidence ellipse sway area and for velocity compute equation. In brief, the total area of COP sway was calculated using a $95 \%$ confidence ellipse, which represents an area that encloses $95 \%$ of all COP positions data for a given tria $1^{19}$. This procedure helps to increase the precision of data from sway in both directions. The sway velocity was then represented by the total COP displacement divided by time $(\mathrm{cm} / \mathrm{s})^{19}$. The evidences ${ }^{15-19}$ have supported the use of COP ellipse area and/or mean COP velocity sway to better represent balance measurement with regard to good reliability and validity of data. In the present study, significant results were pointed out on of one these variables, COP velocity, which supports the relevance of our results for literature of issue. Furthermore, this measure is sensitive to detect small postural sway in a little area of space as unipodal support in different populations ${ }^{16}$.

The results of present study are in agreement with previous studies ${ }^{20}$ from other modalities and especially with Leong et al. ${ }^{21}$, who observed that adults practitioners of TKD (from one to three years of training) have better postural balance when compared to sedentary people. Fong et al. ${ }^{22}$ showed that short- and longterm adolescents practitioners of TKD had significantly slower sway than the CG during one-single stance with eyes opened. Although there are differences in the population between the present study (adults) and those from Leong et al. (adolescents) ${ }^{21}$, it is suggested that TKD practitioners present better postural performance compared to untrained participants.
The one-leg stance task may have benefited the TKDG, once the repetition of specific movements induces specific postural adaptations $\mathrm{s}^{21-23}$. The superior upright unilateral stance stability in the TKD athletes may result from the repeated practice of high kicks during training ${ }^{21}$. This would require high level of balance, thus it would improve the postural regulation in unilateral stance ${ }^{24}$. Similar results were seen in judo players, who develop positive motor skills to improve their postural balance from technical movements in unipodal support ${ }^{23}$. Furthermore, some authors suggested that athletes in combat sports such as karate (martial art similar to TKD) would maximize the changes in visual information to maintain upright standing ${ }^{25-27}$. Thus, TKD training may improve the ability to use the visual system to maintain balance ${ }^{26,27}$.

The results herein may be explained by the development of the vestibular system of TKD athletes. Such training involves acrobatic jump and spinning kicks, which would stimulate the vestibular system and increase its sensitivity ${ }^{27}$. Fong et al. ${ }^{22}$ found that TKD training speeds up the development of vestibular function. Therefore, adolescents who practiced TKD improved their vestibular function so that they could better stabilize in unilateral stance than their non-TKD counterparts. In our study, the athletes have been practicing TKD since their childhood. This can reduce their chances of injuries with falls during training. Furthermore, the somatosensory system also suffers alterations as a result of sports training ${ }^{28}$. For example, judo training would improve proprioception in dynamic situations ${ }^{28}$ similar to gymnastics practice on knee and ankle joint proprioception ${ }^{29}$.

Some limitations in this study need to be considered when interpreting the findings. First, the number of included participants was small. Second, we must be careful to generalize our results to all TKD practitioners, as the population evaluated in this study was the high-performance athletes as compared to control. Future studies are still encouraged to assess the effects of TKD training on postural balance.

Finally, the physiotherapists should consider the use of some TKD movements, such as standing in one leg and reaching a target positioned in front with the contralateral limb, during their clinical practice to improve balance of athletes suffering neuromuscular disorders. 


\section{CONCLUSIONS}

High-performance TKD professional athletes compared to healthy young adults presented lower COP velocity sway during single leg support, which indicates better postural balance than control. These results have any implications on sport rehabilitation programs for balance assessments in athletes.

\section{REFERENCES}

1. Kukkiwon. Taekwondo textbook. 2 ed. Korea: O-Sung Publishing Company, Seoul; 2006

2. Lystad RP, Pollard H, Graham PL. Epidemiology of injuries in competition taekwondo: A meta-analysis of observational studies. J Sci Med Sport. 2009;12(6):614-21.

3. Kazemi M, Chudolinski A, Turgeon M, Simon A, Ho E, Coombe L. Nine year longitudinal retrospective study of Taekwondo injuries. J Can Chiropr Assoc. 2009;53(4):272-81.

4. Kazemi M. Relationships between injury and success in elite Taekwondo athletes. J Sports Sci. 2012;30(3):277-83.

5. Horak FB. Postural orientation and equilibrium: what do we need to know about neural control of balance to prevent falls? Age Ageing. 2006:35 Suppl 2:ii7-ii11.

6. Winter DA, Patla AE. Ishac M, Gage WH. Motor mechanism of balance during quiet standing. J Electromyogr Kinesiol. 2003;13(1):49-56.

7. Lafond D, Corriveau H, Hébert R, Prince F. Intrasession reliability of center of pressure measures of postural steadiness in healthy elderly people. Arch Phys Med Rehabil. 2004;85(6):896-901.

8. Nashner LM. Practical biomechanics and physiology of balance. In: Jacobson GP, Newman CW, Kartush JM, editors. Handbook of balance function testing. San Diego (CA): Singular Publishing Group; 1997. p. $261-79$

9. Tanguy S, Quarck G, Etard O, Gauthier A, Denise P. Vestibulo-ocular reflex and motion sickness in figure skaters. Eur J Appl Physiol. 2008:104(6):1031-7.

10. Suzana MA, Pieter W. Motor ability profile of junior and sênior Taekwondo club athletes. Br J Biomot. 2009;3(4):325-31.

11. Cromwell RL, Meyers PM, Meyers PE, Newton RA. Tae Kwon Do: an effective exercise for improving balance and walking ability in older adults. J Geront A Biol Sci Med Sci. 2007;62(6):641-6.

12. Gerbino PG, Griffin ED, Zurakowski D. Comparison of standing balance between female collegiate dancers and soccer players. Gait Posture. 2007;26(4):501-7.
13. Bressel E, Yonker JC, Kras J. Comparison of static and dynamic balance in female collegiate soccer, basketball, and gymnastics athletes. J Athl Train. 2007:42(1):42-6.

14. Perrin P, Deviterne D, Hugel F, Perrot C. Judo, better than dance, develops sensorimotor adaptabilities involved in balance control. Gait Posture. 2002:15:187-94.

15. Pinsault N, Vuillerme N. Test-retest reliability of centre of foot pressure measures to assess postural control during unperturbed stance. Med Eng Phys. 2009;31(2):276-86.

16. da Silva RA, Martin B, Parreira RB, Teixeira DC, Amorim CF. Age-related differences in time-limit performance and force platform-based balance measures during one-leg stance. J Electromyogr Kinesiol. 2013;23(3):634-9.

17. Winter DA, Patla AE, Ishac M, Gage WH. Motor mechanism of balance during quiet standing. J Electromyogr Kinesiol. 2003;13(1):49-56.

18. Lin D, Seol H, Nussbaum MA, Madigan ML. Reliability COP-based postural sway measures and age-related differences. Gait Posture. 2008;28(2):337-42.

19. Prieto TE, Myklebust JB, Hoffmann RG, Lovett EG, Myklebust BM. Measures of postural steadiness: differences between healthy young and elderly adults. IEEE Trans Biomed Eng. 1996:43(9):956-66.

20. Asseman F. Caron O. Cremieux J. Are there specific conditions which expertise in gymnastics could have an effect on postural control and performance? Gait Posture. 2008;27(1):76-81.

21. Leong HT, Fu SN, Ng GY, Tsang WW. Low-level Taekwondo practitioners have better somatosensory organization in standing balance than sedentary people. Eur J Appl Physiol. 2011:111(8):1787-93.

22. Fong SM1, $\mathrm{Ng}$ GY. Sensory integration and standing balance in adolescent taekwondo practitioners. Pediatr Exerc Sci. 2012 Feb;24(1):142-51

23. Paillard T, Montoya R, Dupui P. Specific postural adaptations according to the throwing techniques practiced in competition-level judoists. J Electromyogr Kinesiol. 2007:17(2):241-4.

24. Paillard T, Noé F, Rivière T, Marion V, Montoya R, Dupui P. Postural performance and strategy in the unipedal stance of soccer players at different levels of competition. J Athl Train. 2006;41(2):172-6.

25. Del Percio C, Brancucci A, Bergami F, Marzano N, Fiore A, Di Ciolo E, et al. Cortical alpha rhythms are correlated with body sway during quite open-eyes standing in athletes: A high-resolution EEG study. Neuroimage. 2007;36(3):822-9.

26. Christelle R, Jacques $C$. Perception de l'orientation visuelle chez des experts en taekwondo. Staps. 2004;65(3):79-96.

27. Tanguy S, Quarck G, Etard O, Gauthier A, Denise P. Vestibulo-ocular reflex and motion sickness in figure skaters. Eur J Appl Physiol. 2008;104(6):1031-7.

28. Perrot C, Deviterne D, Perrin PH. Influence of training on postural and motor control in a combative sport. J Hum Mov Stud. 1998;35(1):119-36.

29. Lephart SM, Giraldo JL, Borsa PA, Fu FH. Knee joint proprioception: a comparison between female intercollegiate gymnasts and controls. Knee Surg Sports Traumatol Arthrosc. 1996;4(2):121-4. 